\title{
Sustainable Warehouse Management
}

\author{
Kah-Shien $\operatorname{Tan}^{1}$, M. Daud Ahmed ${ }^{2}$ and David Sundaram ${ }^{1}$ \\ ${ }^{1}$ University of Auckland, New Zealand, ${ }^{2}$ Manukau Institute of Technology, New Zealand \\ ktan075@aucklanduni.ac.nz, Daud.Ahmed@manukau.ac.nz,d.sundaram@auckland.ac.nz
}

\begin{abstract}
Sustainable warehouse is about integrating, balancing and managing the economic, environmental and social inputs and outputs of the warehouse operations. Sustainability is a core value to many businesses but they find it hard to implement in their current business setting especially when they use third party logistics management system like warehousing and distribution in their supply chain business network. This paper explores the application of sustainability principles in the context of warehouse storage and distribution management and introduces a sustainability model for setting up of a warehouse or transformation of an existing warehouse that provides the storage services. The model incorporates the usage of third party transportation sy stems for supply and distribution services.
\end{abstract}

Keywords: Sustainable warehouse management, sustainability modelling, system dynamics

\section{Introduction}

Sustainable management is a concept for integrating and balancing economic, environmental and social dimensions [1], commonly termed as TBL or triple bottom line [2], into decision making [3]. Sustainable management of businesses is the roadmap to achieving the present needs of society without compromising the opportunities of future generations [4]. The Min istry for the Environment [5] observes that New Zealand may not be able to look after its people and offer them a place they want to live in if businesses and society do not stop and reverse the damage to the environment. New Zealand's clean and green image is now becoming frag ile [6] and its sustainability status is declining in many aspects of its production and consumption of goods and services over the last ten years. The Ministry for the Environment [5] also stresses that New Zealand will struggle to provide an adequate standard of living for its citizen in the future if the current trends are not broken. Over the past 100 years, New Zealand's energy use has doubled every 22 years and its energy intensity is the highest among the Organisation for Economic Cooperation and Development (OECD) countries. The Green Office observes that New Zealand is the seventh worst of 23 International Energy Agency (IEA) countries in terms of energy use per dollar of GDP [7]. Additionally, in the last 15 years, the amount of solid waste produced in the Auckland Region has almost doubled. 
Ministry for the Environment emphasises on the performance of the three sustainability dimensions [5] and the New Zealand Business Council for Sustainable Development stresses that sustainability is not just an option but a requirement for many businesses in New Zealand [9]. Sustainability is now becoming a necessity as stakeholders and society place higher expectations on companies, expecting them not only to be profitable businesses but also to be socially [10] and environmentally responsible for their actions. While many companies have jumped onto the sustainability bandwagon, sustainability is still a relatively new concept to most businesses as far as strategy development, business process transformation and implementation are concerned.

Economic, environmental and social dimensions of businesses are inter-related (Fig. 1.) and any change in the objectives of a dimension greatly influences the other two dimensions. Therefore, if the company had considered each of the sustainability dimensions independently and made decisions without considering all possible consequences of their decisions, any attempt to become a sustainable business would be unsuccessful. The first step in transforming a company into a sustainable business is to develop a sustainability vision and sustainability strategies that include sustainability objectives. In order for business strategies to be success ful, they need to be derived from the organisational resources and experiences [11]. However, current sustainability visions and strategies are mostly a personal vision of top management which are not realistically supported by the organisation's resources, processes, and knowledge-base. This lack of consideration and poor execution is mainly due to the lack of frameworks and tools which can foster a real understanding that each of the three dimensions are inter-related and demonstrate the dynamic relationships the three sustainability dimensions have with each other.

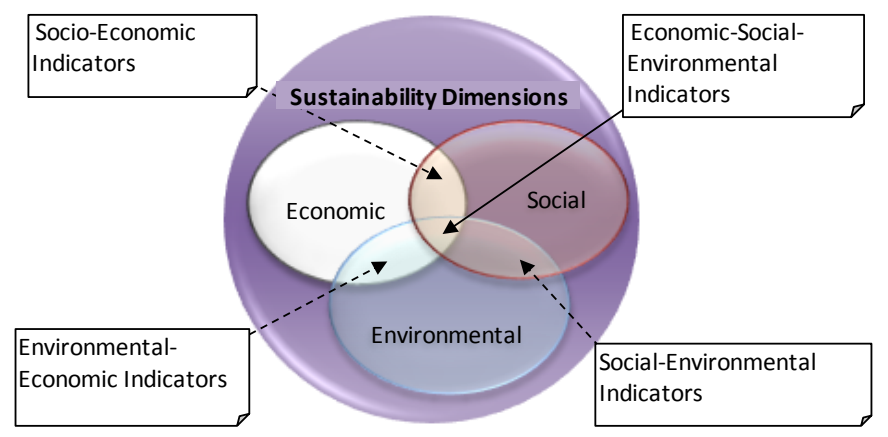

Fig. 1. Inter-relationship among the sustainability dimensions of the business

This paper explores sustainable warehouse modelling in the context of an organisation that provides storage and transportation services. We model the sustainability is sues of warehouses in general and then apply it in particular to the firm under study. We close the paper with a brief description of the implementation of the models and the development of a system that enables us to monitor the triple bottom line scorecard. 


\section{Sustainable Warehouse Management}

Sustainable supply chain management is the "Management of raw materials and services from suppliers to manufacturer / service provider to customer and back with improvement of the social and environmental impacts explicitly considered." [9] Decreased barriers to trade and improved technology [12] has allowed businesses and supply chains to expand across regions and countries, further increasing the need for the sustainable management of supply chains. Furthermore it is inadequate for businesses to promote sustainability only within their own company, entire supply chains have to be managed in a sustainable fashion in order for business to remain competitive. Benefits of sustainable supply chain management include increased brand appeal, sales loyalty and stakeholder satisfaction as well as reduced negative impacts on society and the environment [9]. Having a sustainable supply chain would also improve transparency and visibility along the chain allowing companies to be able to respond quickly to changes in the market and other situations.

One of the key components within the supply chain is warehousing. Most warehousing and transportation companies have little regard for the environmental impacts of their actions and do not understand the social consequences of their business activities. These companies consider factors such as cost effectiveness and customer satisfaction as the main performance indicators [13], [14]. Linton and Quariguasi Frota Neto argue that being involved in the storage and transportation of goods, these companies have to recognise the importance of transforming their current business model into a sustainable one. An added impetus to the argument is that vehicle emissions are one of the major sources of pollution.

This research undertakes a real-life sustainable warehouse management project in Auckland for an ISO certified warehousing company. The company provides storage facilities for chemical and food items in Auckland and Christchurch for various customers and delivers the goods to various manufacturing and retail businesses all over New Zealand. Various small to large transportation companies are also working in collaboration with the company in the transportation and delivery process. The warehousing company is growing rapidly and thus wishes to increase capacity by establishing more warehouses. The company's operations management processes are well-defined but due to shortage of skilled workforce, recent developments in health and safety, and environmental regulations as well as pressures from the sustainability aware members of its supply-chain, clients and the end users, the company decided to redesign the business processes for the new warehouses that follow sustainability management approach and achieve competitive advantage within a short period. Major issues like employee retention, compliance and environmental footprints, and financial return are associated with the location of the warehouse. Therefore, the selection of warehouse location is an important strategic issue that would have a major impact on economic, environment and social dimensions of the entire management of the business. We highlight some of these is sues in the remaining part of this section.

Due to the nature of the goods handled, the company has to meet a large variety and number of compliance regulations such as health and safety, hazardous goods storage and handling, food items storage and handling, environmental compliance to name a few. It is obligatory for all employees to be highly trained in the compliance 
processes. Thus it is hard to recruit skilled employees ranging from managers to warehouse operators who are needed to handle the chemical and food items. Ideally, the company would want zero employee turn over in order to minimise new staff training costs and achieve beyond the statutory compliance obligations to become a leader in the niche market.

Currently, the company's distribution system is entirely dependent on the road transportation network. Vehicle pollution is one of the biggest causes of environmental pollution in New Zealand, thus in the effort towards becoming a sustainable business, the warehouse should be located such that the pollution generated is minimised. This can be achieved by either locating closer to the end users or in a place that enables them to utilise alternative forms of environment friendly transportation. In the pursuance of providing maximum stakeholder satisfaction, the company also intends to invest a good proportion of their budget in in formation and decision support systems to aid effective decision making. The major stakeholders of the company are customers, retail/ manufacturing centres, end consumers, transportation companies, consultants, accountants, employees and government departments.

With the aim of helping the company become a leading sustainable warehouse management company, the authors undertook a research project to develop a sustainability systems model. While keeping the is sues discussed earlier in mind, this model will be used to simu late and analyse sustainability key performance ind icators determined from the critical success factors of a sustainable warehouse. The model will also support them in strategic decision making towards becoming a leading sustainable warehouse management company.

A sustainable warehousing company would not only have to consider the economic factors, such as rent and operations costs, but also balance the social and environmental effects that occur within the warehouse compound as well as its surrounding vicinity. This research places an emphasis on developing a balanced scorecard in conjunction with a sustainability model to help select a suitable location for a warehouse. The selection depends on the supply and delivery locations of the customers and the end users, transportation choices to and from the warehouse, and skilled staff availability and their job satisfaction.

\section{Modelling the Sustainable Warehouse}

The sustainable warehouse management system can easily be broken down into simpler and more manageable parts for modelling [15]. However, modelling in isolation is not sufficient; it is the relationship and interaction between the parts that are important [16]. Sustainability models can be developed using a systems thinking approach and this helps in shifting the focus from individual effects to interconnected systems [17] to shape organisations and their processes. Therefore the sustainable warehouse management model needs to address the inter-relationships of economic objectives, employee welfare and minimisation of environmental impacts in an integrated fashion. 
Maani and Cavana observe that the study and management of a complex feedback system can only be done using system dynamics/ systems thinking modelling methodologies [18]. Only the study of the system as a whole will lead to effective solutions and establish a win-win-win proposition for the three dimensions. Therefore iThink, a modelling tool that supports system dynamics, was chosen. iThink is useful for modelling dynamic relationships such as social issues (e.g. health, safety, recruitment, retention, working hours, wage, job satisfaction, training, etc.); environmental issues (e.g. carbon minimisation, recycling, solid waste, air pollution, water pollution, etc); and economic issues (e.g. capital investment, warehouse rent, transportation cost, handling cost, packaging, information systems, hire cost, etc). Firstly, a cause-effect diagram was constructed to demonstrate the interdependence among the various issues and present an influence diagram. Then, the relationships among the factors were established.

Subsequently, an interactive game which demonstrates the interdependent relationships between the three sustainability dimensions was created. This allows users to gain a better understanding of how a decision will affect each of the three sustainability dimensions.

While the warehouse's location was the main decision problem, other decision parameters were required to design a sustainable model. Some of the major decision parameters include:

- Capital investment : to imp rove staff efficiency and reduce manual labour

- Number of emp loyees : to ensure employees are not overworked

- Emp loyee Training: to ensure high employee productivity and effectiveness and continuous up skilling

- Carbon minimisation: carbon credits, planting trees and air filtering

- Transportation decisions: various modes of transport have significant differences in carbon emissions

A sustainability scorecard was created to monitor the status of various key sustainability performance indicators. Some of the main tracking parameters include Cash flow, Warehouse utilisation, Carbon emissions and minimisations, Order processing time, Employee job satisfaction, Social and environmental impacts on surrounding areas (e.g. nearby residents).

\section{High Level View of Sustainable Warehouse Management}

Fig. 2. represents a high level view of a sustainable warehouse model. The interdependencies of the three sustainability dimensions are depicted by arrows cutting across dimensions. The tradeoffs and interdependent relationships are further discussed in Section 6.

In a warehouse, Goods processing involves processing of inward goods and orders. The rate of processing is determined by the staff's level of job satisfaction and productivity. If the employees are not able to process the required orders, the customers' satisfaction decreases leading to poor business relationships. Once the 
orders have been processed, they are transported to the customer's clients. The process of delivering goods to their destinations results in large amounts of carbon emissions produced by the transportation fleet. In order to offset the carbon emissions, at least one of the Carbon minimisation activities will have to be performed, leading to an increase in costs.

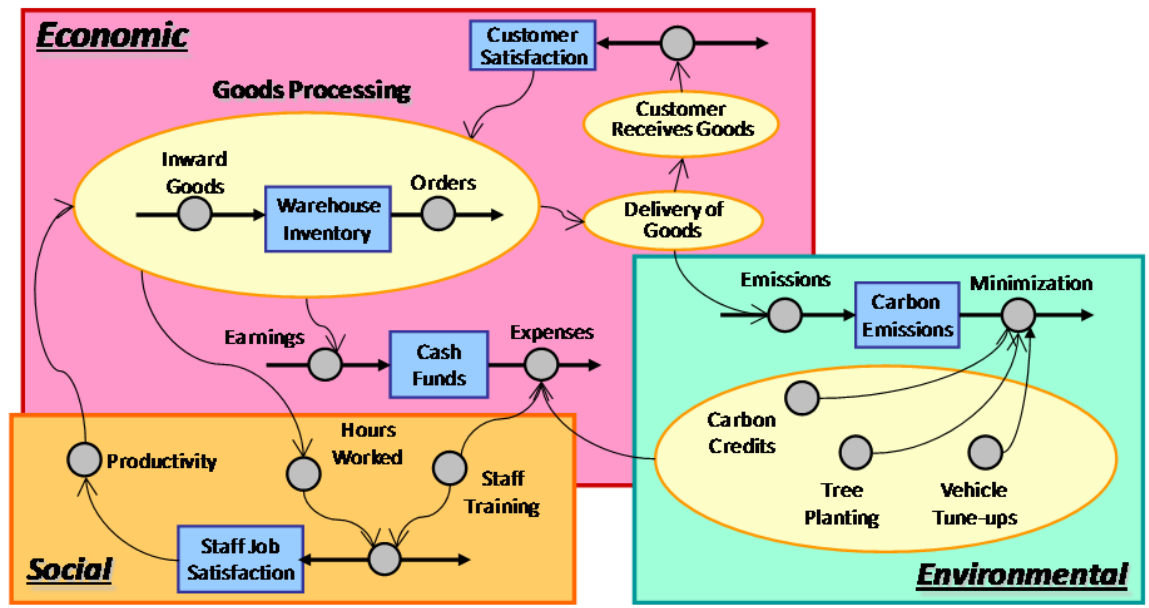

Fig. 2. High level view of a sustainable warehouse model

\section{System Dyna mics Warehouse Management Models}

This section discusses the individual dimensions of the warehouse management model that was developed using system dynamics modelling concepts. Before discussing the dynamics of a sustainable warehouse model, the purpose of each element used in the model is defined. In this instance, a stock and flow model was used to represent the sustainable warehouse model. Elements of a stock and flow model consist of: Stocks, Flows, Converters and Connectors. Each of these elements is further described below.

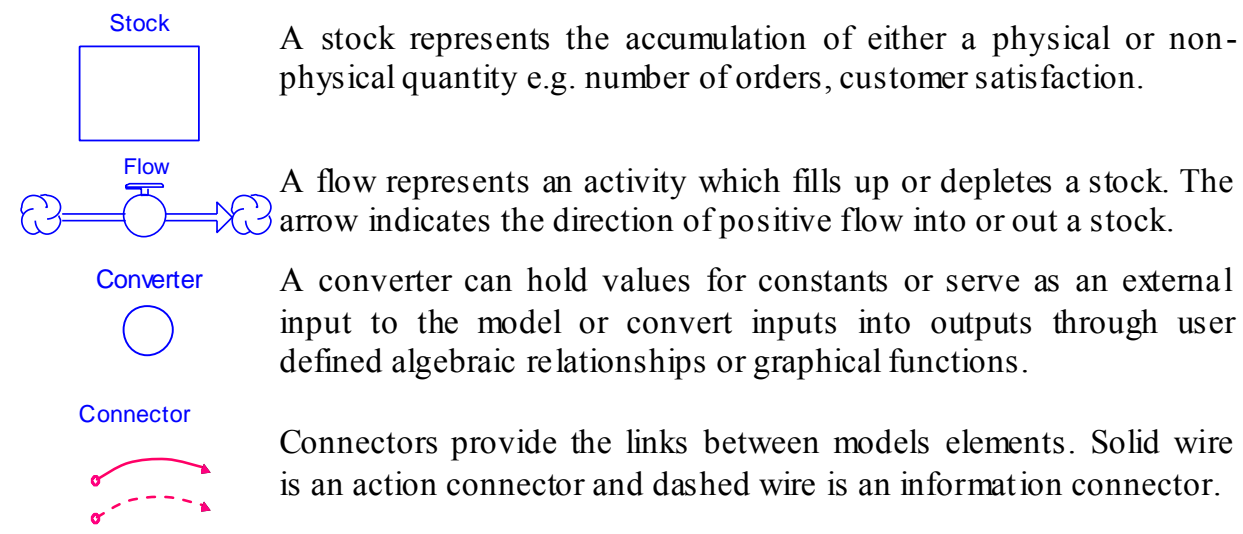




\subsection{The Economic Model}

Fig. 3. is a snapshot of the main economic model of a sustainable warehouse. The stock that is central to the economic model is Warehouse inventory. When a customer sends an order to the warehouse, it is added to the Order backlog. The number of staff (i.e. Hours available for processing orders) and inventory on hand will determine the number of orders processed (Orders filled) and delivered. Any orders that cannot be processed, due to the shortage of either staff or inventory, will remain in the Order backlog until the next run. Warehouse utilisation which considers the effectiveness and efficiency of space usage is also an important economic factor to monitor in the warehousing business.

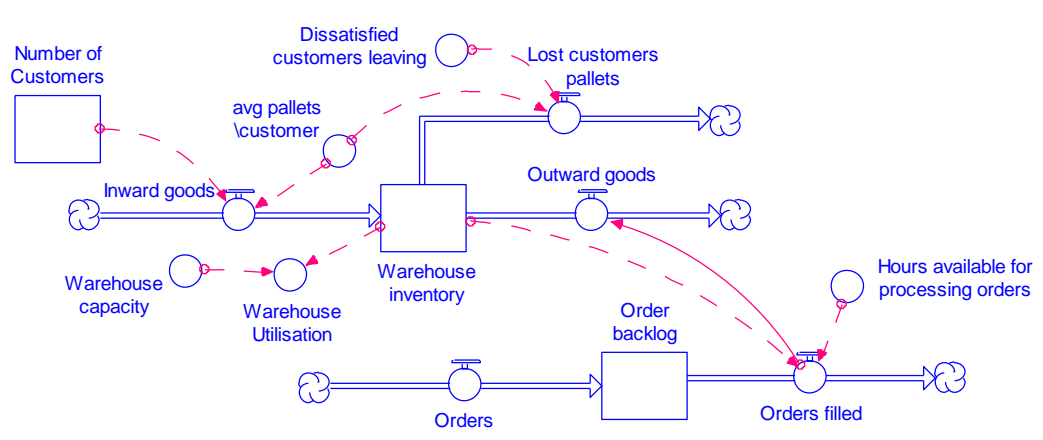

Fig. 3. Economic model of a sustainable warehouse

The warehouse company wants to maintain a high capacity utilisation rate to ensure maximum profits. Thus if utilisation is consistently low, it is an indication that the company should seek to obtain new customers by means of promotions or advertising. On the other hand, if the warehouse is over utilised, the company will have to consider increasing their warehouse capacity or rent short-term storage facilities for excess inventory at a greater than average cost. The company should also try to maintain a high level of customer satisfaction by ensuring that goods are delivered on time or the company might run the risk of losing some of their customers.

\subsection{The Envir onmental Model}

A high level model showing a few factors that influences the environmental dimension is illustrated in Fig. 4. This model shows the main inflows (Emissions) and outflows (Minimisations) of the Carbon emissions stock. Carbon emissions (Total transportation emissions) are generated by the company's transportation fleet comprising of vans, small and large trucks. As the vehicles are highly utilised, their efficiency deteriorates over time thus producing higher levels of carbon emissions. The warehouse company can minimise this by regularly maintaining and upgrading their vehicles (Transportation fleet upgraded). The company may offset their carbon emissions by planting trees (Carbon absorption by trees) or purchasing Carbon credits. 


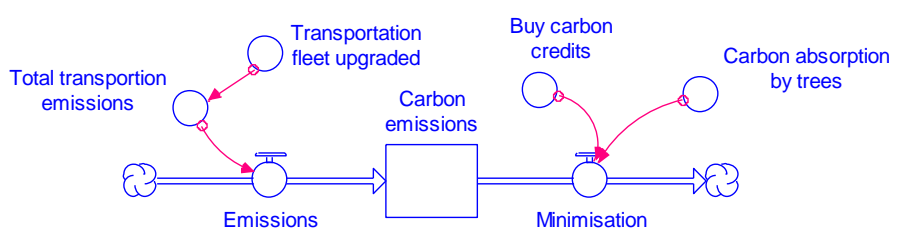

Fig. 4. Environmental model of a sustainable warehouse

\subsection{The Social Model}

The social dimension of the sustainable warehouse is very complex and contains many elements. For the sake of simplicity, a simplified social dimension model is presented in Fig. 5.. This model represents the social effects of a warehousing company with respect to its employees. The main stock in this model is Job Satisfaction. It is an index which has a maximum value of 100 . The job satisfaction of the warehouse employees is very important. This will be discussed further in Section 6.

Factors such as hours per employee per week (Work hours/person), the amount of Staff training and support provided and Capital investments, like new equipment and software to aid employees in their work, all have an effect on their level of job satisfaction. If emp loyee Job satisfaction drops below a certain level, staff members start to leave the company, resulting in having to hire more staff, thus incurring recruiting and new staff training costs.

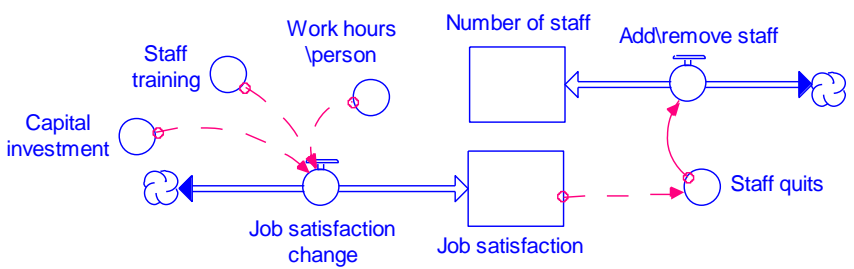

Fig. 5. Social model of the sustainable warehouse

\section{Inte ractions between the Sustainability Models/Dimensions}

Having briefly discussed the inter-relationships of the sustainability dimensions in Section 4 and Fig. 2, this section is dedicated to demonstrating some of the relationships between the three sustainability dimensions in the sustainable warehouse model.

\subsection{Envir onmental - Economic - Social}

In order for the company to move towards sustainability, they have to consider and balance the tradeoffs between minimizing costs as well as being both environmentally 
and socially responsible. As previously shown in Fig. 4, so as to offset their Carbon emissions, the company will have to purchase Carbon credits, plant trees or minimise the emissions from their transportation fleet. All three Carbon minimisation options will increase their expenses, which might lead to lesser funds being made available for Staff training and Capital investments. Inadequate staff training and capital investments will lead to poor job satisfaction and low productivity. This is further discussed in the Section 6.2.

Another factor the company needs to consider is that the trees will require a couple of decades before they are able to provide the full benefits of carbon absorption. Thus, they may wish to consider purchasing Carbon credits as a short term solution while planting trees as the long term but more cost effective solution. In either case, the company should minimise inevitable carbon emissions by maintaining vehicle efficiency as it is important to consider the effects of carbon emissions on society, especially in areas along delivery routes.

\subsection{Social - Economic}

Following on from Section 6.1, choosing not to hire more staff when required might result in short-term savings but will be detrimental to the company in the long run. This is because, the number of staff determines, on average, the number of Hours available for processing orders. Thus, a shortage of staff will result in employees having to work excessive hours over a long period of time to try reduce the Order backlog. This results in decreased Job satisfaction due to increased stress and tiredness. Poor job satisfaction will also lead to low morale and higher risks of making mistakes, therefore causing a drop in overall productivity. A drop in productivity means the average order processing time also rises, further increasing the Order backlog.

High levels of backlog will lead to poor customer satisfaction and retention. If a customer is lost, not only will the company have to spend more money finding new customers, the loss of reputation and increased negative word of mouth will have harmful long term effects.

\section{Implementation of the Sustainable Warehouse Models}

To implement the models, the modelling software tool iThink 9.0.2, from iSee Systems, was used. iThink uses stock and flow diagrams to model and simulate processes and scenarios. It shows you the outcomes of certain user-defined inputs and communicates the interdependencies between processes and problems. Outputs can be displayed in the form of graphs, tables and warning gauges. In this instance, dynamic systems modelling techniques were used in the creation of this model. The process of creating the model in iThink was an iterative process. It started with a very simple warehouse inventory model (Fig. 3.) consisting of one stock (Warehouse Inventory), one inflow (Inward goods) and one outflow (Outward goods). This model was then tested to ensure that the relationships defined were correct. Once, this was verified, more elements such as Order Backlog and Number of customers were added. Again 
this was tested before new elements were added. The whole process of building the entire model was carried out in this manner to allow ease in identify ing errors in the model.

\subsection{System Walkthrough}

Fig. 6. shows the main user interface of the simulation model. There are six main sections on this user interface; the Sustainability Scorecard, the Economic inputs, the Social inputs, the Environmental inputs, the Comparative Charts and the Run section. The Sustainability Scorecard consists of three indicators; Revenue, Job Satisfaction and Carbon Emissions. Revenue is the average revenue from all three locations. If the decision maker clicks on Details, the decision maker sees another page with the individual components that affect revenue. Thus if Revenue enters the "High Alert" (red) stage, the decision maker is then able to drill further down into the details to determine which type of expenses was causing a drain in finances. For example, the warehouse may have been paying too many employees while there is little work to be carried out. This indicates that the decision maker might have to fire an employee to reduce costs. The decision maker can carry out the same operations for the social indicator, Job Satisfaction, and the environmental indicator, Carbon Emissions. The decision maker also has the option, at any time, of reviewing previous simulation results for the three main indicators by choosing one of the choices in Comparative Charts. The Custom Detail button leads the decision maker to a page where they would be able to customise their own graphs or data tables.

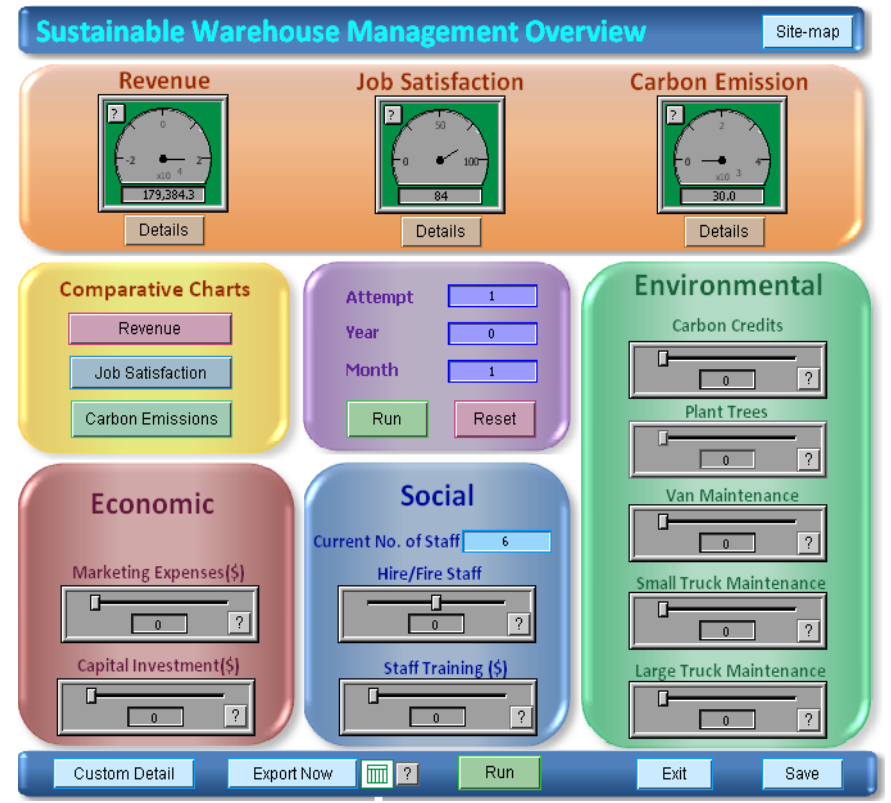

Fig. 6. The Sustainable Warehouse Management Simulation Interface 
The Economic input section allows the decision maker to determine the amount of Marketing Expenses (to obtain new customers) and Capital investment for each month. These values are reset to zero after each month. The Social input section allows the decision maker to define the level of Staff Training available to improve job satisfaction and Hire or Fire Staff according to the amount of work available. In the Environmental section, the decision maker Buys Carbon Credits or Plants Trees to offset their carbon emissions. They are able to optimise the efficiency of their transportation fleet by choosing a transport mode to upgrade or enforce a new selection rule for the transportation company.

To begin the simulation, the user chooses all the values of the inputs that are desired, and then clicks the Run button. The simulation runs for one quarter and pauses to allow the user to review the effects of the decisions made. The next few subsections will discuss the prototype in more detail.

\subsection{Economic Indicators}

The Economic Indicators page, as seen in Fig. 7, provides the decision maker with more economic indicators to help monitor and assess the situation. This page will display a line chart of Revenue, Income and Expenses. This visualisation will allow decision makers to gain a better understanding and view of how the financial situation has changed over time. In addition, indicators of Customer Satisfaction and Warehouse Utilisation are provided as well. Both these indicators considered economic factors as they have an impact on the company's financial status. For example, poor customer satisfaction will lead to customers leaving the company and taking their business to competitors. This will result in a decrease of income as well as an increase in expenses required to obtain new customers.
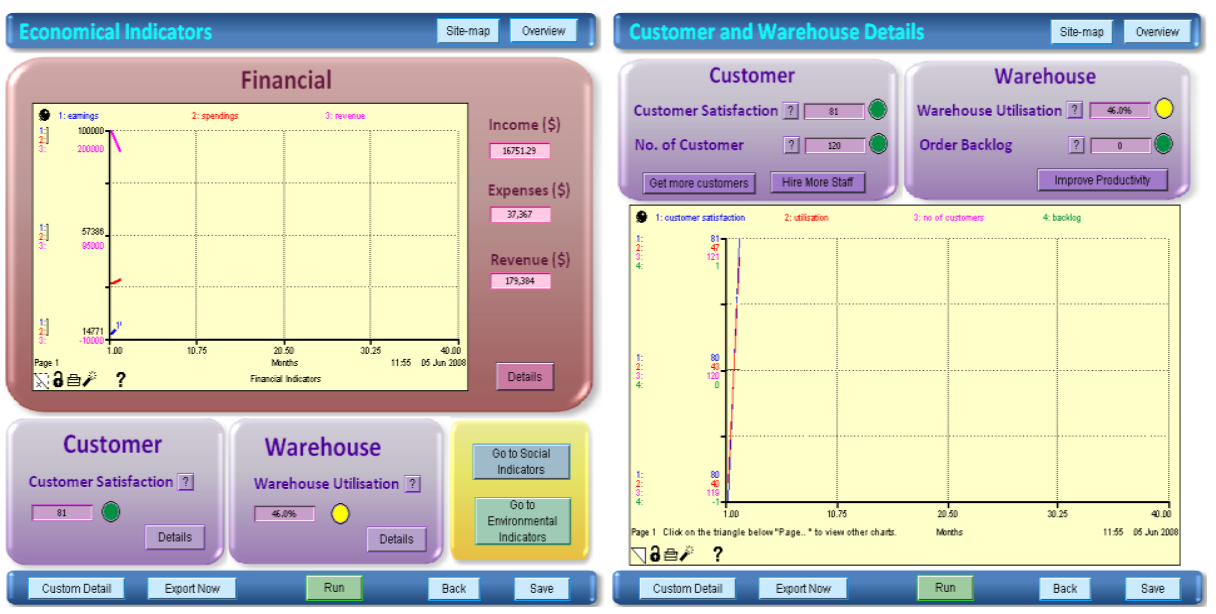

Fig. 7. Some Economic Indicator Pages

Poor warehouse utilisation, which could result from poor customer satisfaction, would mean that the warehouse company is mot maximising their profit potential and would 
be incurring increased overhead costs per unit of storage used and reducing their cost efficiency. By clicking on Customer Satisfaction or Warehouse Utilisation "Details", the decision maker would be led to a page with more details regarding customers and the warehouse. This page provides the decision maker with information such as Order Backlog, Warehouse Inventory, Inward Goods and Outward Goods. Although not shown, the decision maker can also view a more detailed breakdown of Income and Expenses on another page. The next subsection discusses the Social Indicator pages.

\subsection{Social Indicators}

The three main social indicators consist of Average Processing Time/Pallet, Hours/Person/Month and Job Satisfaction. Fig. 8. shows the main Social Indicators page displaying the three values in the form of status dials and a line chart. The status dials change between Red, Yellow and Green according to pre-defined limits. For example, the Hours/Person/Month indicator turns Red when employees are working more than 55 hours per week. This provides a visual aid to alert the decision maker about the seriousness of the situation. In addition, a pop-up message will appear to notify the user regardless of which page they are currently viewing.

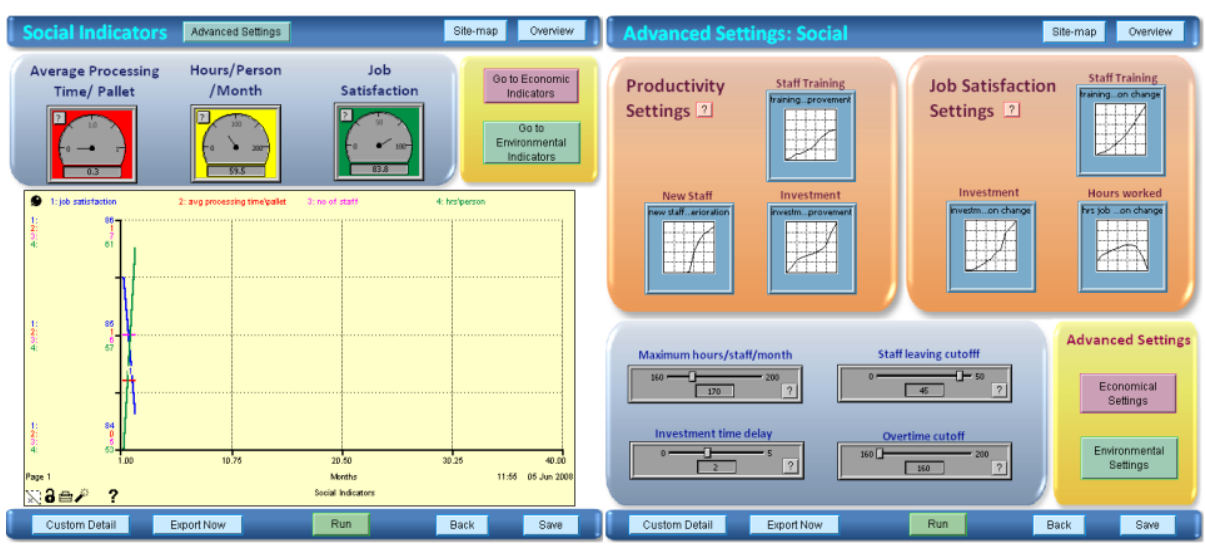

Fig. 8. Some Social Indicator Pages

A line chart, which plots these indicators, not only provides the decision maker with a visual aid but allows the decision maker to gain a better understanding of the relationships each of these indicators have with each other. For example, the line chart will clearly show, as the number of hours worked increases over the limit, employee job satisfaction starts to drop over time. The Advanced Settings: Social page provides the more experienced decision maker with the ability to change lower level details and relationships. One such example is the relationship between Staff Training and Productivity or the number of hours worked per month that is considered to be overtime (Overtime Cutoff). Advanced settings are also available for Economic and Environmental factors. 


\subsection{Environmental Indicators}

This subsection gives a brief discussion of the Environmental Indicator pages in the Sustainable Warehouse Management prototype. The main Environmental Indicators page hows the number of trees that have been planted as well as the number of trees ready to be sold. In order to support the decision maker, the Number of trees required to offset current cumulated emission levels are also provided to guide the user towards making more effective decisions.

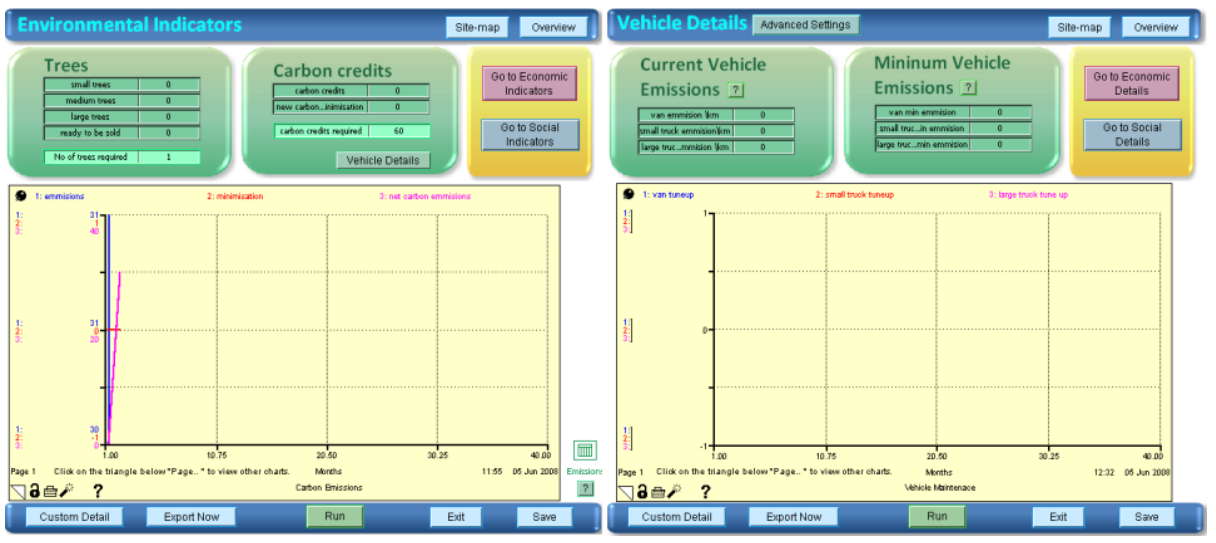

Fig. 9. Some Environmental Indicator Pages

A similar guide is provided for carbon credits (i.e. Carbon Credits required to offset current cumulated emission levels). Similarly, visual aids are provided in the form of line charts. The Vehicle Details page provides the decision maker with details such as current vehicle emissions per distance travelled. Along with this information are the minimum levels (i.e. most fuel efficient) of carbon emissions for each vehicle type. This allows the users to make more informed decisions on which vehicle type requires maintenance. For example, if current van emissions are very close to the minimum possible emissions, then the decision maker will know that it would be a waste of money to perform maintenance on the van fleet. The money would be better utilised maintaining a less fuel efficient fleet or spent on other expenses that provide better value to the company in terms of economic, social or environmental terms.

\section{Support for Decision Makers}

As discussed in earlier sections, the prototype provides the decision maker with various forms of support that guide them through the decision making process. These guides range from the use of status alarms and notifications to the use of visual aids to enhance learning and understating of various relationships in the context of warehouse management. To aid the warehouse executives in making strategic decisions, the user interface of the sustainability model alerts the user with various notifications during the course of the simulation. For example, if the cash flow is low, 
a message pops up to notify the user that their cash flow is unsustainable. It also alerts the user if the employees are over worked; customer satisfaction level has decreased to a non-acceptable level; investment is required in employee training; warehouse location is not suitable considering the end user location or capital investment; monthly operational costs and overheads are too high; high customer turn over or emp loyee resignation due to poor communication or handling etc.

Usability and autonomy concepts were also kept in mind while designing the prototype and user interface. This prototype caters from novice users, who may only navigate through 3 or 4 main pages, to the expert users who may take advantage of the advanced functionality available in the prototype. The interface was kept simple and designed with ample "Help" or "?" buttons that provide the decision makers with a description of various concepts or explanations to improve user autonomy. Colour templates as wells as repeated and common items were kept consistent so as not to confuse the user and improve usability. For example, as seen in Fig. 7. to Fig. 9., Sitemap, Overview, Run and Save buttons were kept in the same locations of each page allowing decision makers to locate them easily and intuitively.

\section{Conclusion and Future Research}

Sustainable business management and operations are a pre-requisite for the transformation of existing businesses into sustainable ones. This involves the development of sustainable policies, identifying the problems, assessing options for addressing the problems, considering inter-connected is sues, and taking into account the long-term pros and cons. But to be able to explore such issues, an environment that enables us to simulate the complex interdependencies between the social, economic, and environmental dimensions is required. This paper has gone some distance in proving that it is possible to model the interconnectivity between disparate sustainability dimensions. The testing, validity, usefulness and entirety of the model in the context of a real warehouse for day-to-day decision making are still under progress and will be published as an empirical case study.

\section{References}

1. WBCSD: Sustainable Development Reporting: Striking the Balance. World Business Council for Sustainable Development (2004)

2. GRI: Sustainability Reporting Guidelines. Retrieved 24 March, 2007, from http://www.globalreporting.org/GRIGuidelines/2002/gri_2002_guidelines.pdf (2002)

3. Elkington, J.: Cannibals with Forks: The Triple Bottom Line of Sustainable Development. Oxford, Capstone Publishing (1997)

4. Bruntland, G.: Our Common Future: The World Commission on Environment and Development. Oxford University Press, Oxford (1987)

5. Ministry for the Environment.: The Government's Approach to Sustainable Development. New Zealand (2004) 
6. Parliamentary Commissioner for the Environment.: Creating Our Future: Sustainable Development for New Zealand. Wellington, Office of the Parliamentary Commissioner for the Environment (2002)

7. Green Office.: Green Office Guide. Retrieved 28 October, 2003, from www.greenoffice.org.nz (2002)

8. Ministry for the Environment.: Ecological Footprint Calculator. Retrieved 02 March 2004, from http://www.environment.govt.nz/footprint/input.html (2004)

9. NZBCSD.: Business Guide to a Sustainable Supply Chain: A Practical Guide. Retrieved 11 Nov, 2007, from www.nzbcsd.org.nz/supply chain (2003)

10. Ansett, S.: Mind the Gap: A Journey to Sustainable Supply Chain. Employee Responsibilities and Rights Journal 19(4): 9 (2007)

11. Lynch, R. (2005). Corporate Strategy, Financial Times Press.

12. Jorgensen, A. L., Knudsen, J.S.: Sustainable competitiveness in global value chains: how do small Danish firms behave? Corporate Governance 6(4) (2006)

13. Linton, J. D., Klassen, R., Jay araman, V.: Sustainable Supply Chains: An Introduction. Journal of Operations Management 25(6): 8 (2007)

14. Quariguasi Frota Neto, J., Bloemhof-Ruwaard, J.M., Nunen, J.A.E.E. van, Heck, H.W.G.M. van: Designing and evaluating sustainable logistics networks. International Journal of Production Economics 111(2): 13 (2008)

15. van Es, R., Ed.: Dynamic Enterprise Innovation, Exclusive Baan Web edition (1998)

16. Ahmed, M.D. and Sundaram, D.: A Framework for Sustainability Modelling and Reporting. The International Journal of Environmental, Cultural, Economic and Social Sustainability. Volume 3, Issue 2. pp. 29-40 (2007)

17. Ferguson, G., Dakers, A., Gunn, I.: Sustainable Waste Management: A Hand Book for Smaller Communities. New Zealand, Ministry for the Environment (2003)

18. Maani, K. E., Cavana R. Y.: Sy stems Thinking and Modeling: Understanding Change and Complexity, Pearson Education New Zealand Ltd (2000) 